\title{
POLUSI CAHAYA VIDEOTRON PADA PERSIMPANGAN JALAN TAMAN MENTENG BINTARO
}

\author{
Adi Ismanto ${ }^{1}$, Fivanda $^{2}$, Endah Setyanigsih $^{3}$ \\ ${ }^{1}$ Program Studi Desain Interior, Universitas Tarumanagara \\ Email: adii@fsrd.untar.ac.id \\ ${ }^{2}$ Program Studi Desain Interior, Universitas Tarumanagara \\ Email: fivanda@fsrd.untar.ac.id \\ ${ }^{3}$ Program Studi Teknik Elektro, Universitas Tarumanagara \\ Email: endahs@ft.untar.ac.id
}

\begin{abstract}
Architectural lighting design aims to improve the image and aesthetics of an area or building at night known as the concept of city beautification, the lighting must also be able to meet the criteria of safety, orientation and security when implemented in areas or buildings with complex activities such as in an area adjacent to the traffic flow. Technological advances resulted in the change of commercial media communication facilities, such as static billboards turned into LED videotrons. The placement of videotrons needs to be considered on roads with motorized traffic flow, as it allows for the risk of accidents, as well as light pollution especially at night. This study used The Post Occupancy Evaluation (POE) method, the extent of the influence of videotron light on the comfort of driving a motor vehicle at the intersection of videotron Menteng Bintaro Park. The result of this research that the placement of videotron is the policy of local government, vendors and environmental managers by paying attention to the AMDAL before and after the facilities are installed, with road safety complementary facilities such as road boundaries and shock lines. Information about commercial advertisements on videotron Taman Menteng Bintaro as much as $80 \%$ for pedestrians and motorists get the information, compared to motorists as much as $60 \%$ do not get information. The light effect of videotron greatly affects the surrounding environment and there is a glare effect of light that changes suddenly with results for pedestrians (80\%), motorists (60\%) and the least of the motorists (50\%), because of the more comfortable condition in driving.
\end{abstract}

Keywords: City beautification, videotron, light polution, visual perception, Bintaro streets.

\begin{abstract}
ABSTRAK
Desain pencahayaan arsitektural bertujuan untuk meningkatkan citra dan estetika sebuah kawasan atau bangunan pada malam hari yang dikenal dengan konsep city beautification, pencahayaan tersebut juga harus mampu memenuhi kriteria keselamatan, orientasi dan keamanan ketika diimplementasikan pada kawasan atau bangunan dengan aktivitas yang kompleks seperti pada sebuah kawasan yang berdekatan dengan arus lalu lintas. Kemajuan teknologi mengakibatkan perubahan sarana komunikasi media komersial, seperti papan reklame yang statis berubah menjadi videotron LED. Penempatan videotron perlu diperhatikan pada jalan dengan arus lalu lintas kendaran bermotor, karena memungkinkan untuk terjadinya resiko kecelakaan, serta polusi cahaya terutama pada malam hari. Penelitian ini menggunakan metoda Post Occupancy Evaluation (POE), sejauh mana pengaruh cahaya videotron terhadap kenyamanan mengemudi kendaraan bermotor di persimpangan videotron Taman Menteng Bintaro. Hasil penelitian ini adalah bahwa penempatan videotron merupakan kebijakan Pemda, vendor dan pengelola lingkungan dengan memperhatikan AMDAL sebelum dan sesudah fasilitas terpasang, dengan fasilitas pelengkap keamanan jalan seperti batas jalan dan garis kejut. Informasi mengenai iklan komersial pada videotron Taman Menteng Bintaro sebanyak $80 \%$ untuk pejalan kaki dan pengendara mobil mendapatkan informasinya, berbanding terbalik dengan pengendara motor sebanyak $60 \%$ tidak mendapatkan informasi. Efek cahaya dari videotron sangat mempengaruhi lingkungan sekitar dan terjadi efek silau dari cahaya yang berubah secara tiba-tiba dengan hasil untuk pejalan kaki (80\%), pengendara motor $(60 \%)$ dan paling sedikit dari pengendara mobil (50\%), karena kondisi yang lebih nyaman dalam berkendara.
\end{abstract}

Kata Kunci: City beautification, videotron, polusi cahaya, persepsi visual, jalan Bintaro. 


\section{PENDAHULUAN}

\section{Latar Belakang}

Salah satu cara untuk meningkatkan citra sebuah kota sebagai tujuan pariwisata adalah dengan mempercantik kawasan-kawasan tertentu yang menjadi ikon dari kota tersebut. Kota yang baik harus mampu menampilkan citra dan dapat dinikmati oleh wisatawan baik pada aktivitas siang maupun malam hari. city beautification merupakan salah satu konsep pencahayaan arsitektural yang mampu mempercantik dan memperkuat citra suatu kota dengan menerangi kawasan-kawasan tertentu dari kota tersebut menggunakan pencahayaan yang atraktif dan dinamis (Erco, 2014).

Saat ini di Jakarta dan Tangerang telah berkembang dengan pesat area-area komersial seperti mal. Kondisi ini seiring dengan meningkatnya perkembangan ekonomi dan kompleksitas masyarakat kota urban seperti Jakarta dan Tangerang. Hal ini juga diikuti dengan pesatnya iklan komersial yang statis dan dinamis seperti penggunaan videotron LED, baik di sekitar kawasan mal dan jalan raya dengan kepadatan lalu lintas untuk menjadi sarana marketing, dengan lokasi yang strategis sehingga lebih dekat ke pengguna.

Konsep city beautification menggunakan pencahayaan buatan yang atraktif dan dinamis mulai diimplementasikan pada bangunan komersial dengan tujuan untuk memperkuat citra kota urban. Hal ini mengakibatkan aktivitas pada sekitar area komersial sangatlah padat dan kompleks bukan hanya sebagai jalur lalu lintas kendaraan tapi juga sebagai jalur pedestrian yang besar. Untuk memenuhi kebutuhan aktivitas dan fasilitas tersebut maka pencahayaan arsitektural yang diperlukan bukan hanya memenuhi konsep city beautification yang menghasilkan pencahayaan yang atraktif dan dinamis, tetapi juga harus memenuhi aspek keselamatan (safety), orientasi (information) dan keamanan (security). Dimana pencahayaan tersebut harus mampu mengakomodir kebutuhan pengguna dengan berbagai latar belakang dan perilaku yang berbeda agar merasa nyaman secara visual dan aman (Zumtobel, 2012).

Permasalahan timbul ketika pencahayaan yang atraktif dan dinamis pada area komersial atau iklan komersial dapat mempengaruhi area sekitar seperti penerangan jalan, lampu lalu lintas dan bahkan saling mempengaruhi dengan pencahayaan dari gedung-gedung lain yang mengakibatkan polusi cahaya yang dapat mengganggu pengguna jalan dan kawasan tersebut.

Polusi cahaya merupakan kondisi cahaya yang berlebih, baik itu berasal dari sumber cahaya alami maupun dari sumber cahaya buatan yang menyebabkan rasa ketidaknyamanan. Polusi cahaya dalam kondisi normal lebih banyak disebabkan oleh sumber cahaya buatan. Cahaya buatan yang dimaksud diantaranya seperti lampu taman, lampu stadion, lampu penerangan jalan, lampu reklame, dan lampu penerangan luar lainnya. International Dark-Sky Association (IDA, 2011) menyebut bahwa meningkatnya polusi cahaya secara luas oleh sumber cahaya buatan tidak hanya merusak pemandangan alam, tetapi juga merugikan lingkungan, konsumsi energi, serta keselamatan dan kesehatan makhluk hidup di sekitarnya. Di Indonesia, polusi cahaya merupakan salah satu bentuk pencemaran lingkungan yang masih kurang memperoleh perhatian (Nurfarida et al., 2017).

Gangguan dari pencahayaan yang atraktif dan dinamis pada area (distrik) bisnis dan komersial adalah pusat dari polusi cahaya yang dinamis, dimana beberapa pencahayaan artistik mengalami flickers seperti LED neon light, laser dan lain-lain, dan pencahayaan tersebut mempengaruhi secara langsung terhadap pengemudi kendaraan dan pengguna lainnya (Liu et al., 2012). Pembahasan lebih jauh bagaimana polusi cahaya pada jalan dan fasade bangunan saling mempengaruhi, dan menghasilkan sebuah metode indeks polusi cahaya menggunakan studi 3-D 
illuminance graph (Saraiji el, 2012). persepsi visual terhadap pencahayaan LED pada secondary skin fasad bangunan komersial yang atraktif dan dinamis mengakibatkan gangguan terhadap pengguna jalan raya (Widyani et al., 2016).

\section{Rumusan Masalah}

Permasalahan yang terjadi akibat penggunaan Videotron pada persimpangan jalan Taman Menteng Bintaro diantaranya adalah:

1. Pengaruh pencahayaan terhadap lingkungan sekitar (polusi cahaya), mengingat kawasan tersebut merupakan kawasan lalu lintas dengan aktivitas yang beragam.

2. Persepsi visual pengguna jalan raya, seperti pejalan kaki serta pengendara kendaraan bermotor. Apakah pencahayaan yang atraktif dan dinamis tersebut dapat mengganggu konsentrasi atau bahkan menyebabkan silau sehingga memungkinkan terjadinya kecelakaan.

3. Efisiensi energi dan isu penggunaan teknologi yang ramah lingkungan.

\section{METODE PENELITIAN}

Metode penelitian menggunakan metode analisis sistemik melalui Evaluasi Pasca Penggunaan (Post Occupancy Evaluation). Evaluasi pasca penggunaan atau dikenal sebagai Post Occupancy Evaluation (POE) didefinisikan oleh Zimring dan Reizenstein (1981) sebagai pengujian efektivitas sebuah lingkungan buatan bagi kebutuhan manusia (Laurens 2005). Metode POE digunakan pada penelitian persepsi visual terhadap pencahayaan LED pada secondary skin fasad bangunan komersial, dengan studi kasus mal Taman Anggrek, dengan melakukan pendataan fisis pencahayaan LED dari fasade bangunan, kemudian melakukan wawancara dan kuesioner terhadap responden pengguna jalan (Widyani et al., 2016).

Sumber data primer diperoleh dari hasil wawancara secara langsung saat penelitian yang dicatat dalam catatan-catatan tertulis, pengamatan langsung (observasi), pengambilan foto, serta pengukuran cahaya. Sumber data sekunder diperoleh dari dokumen-dokumen di tempat penelitian mengenai videotron Taman Menteng Bintaro, sumber literatur mengenai pencahayaan arsitektur, sumber literatur mengenai teori yang digunakan dari buku dan jurnal-jurnal terkait penelitianpenelitian polusi cahaya. Teknik pengumpulan data penelitian ini dilakukan dengan cara wawancara dengan narasumber, yaitu pengguna jalan pada persimpangan Taman Menteng Bintaro. Selain itu dilakukan observasi secara langsung pada lokasi penelitian dengan alat bantu kamera untuk pengambilan gambar dan alat ukur luminansi saat pengambilan data fisis. Oleh karena itu evaluasi pasca penggunaan ini mengandalkan kebutuhan atau program pengguna sebagai kriteria atau tolok ukur keberhasilan suatu penataan lingkungan buatan melalui persepsi pengguna jalan dalam hal ini adalah pengguna persimpangan Taman Menteng. 


\section{HASIL DAN PEMBAHASAN Identifikasi objek penelitian}

Gambar 1.

Signaged Taman Menteng

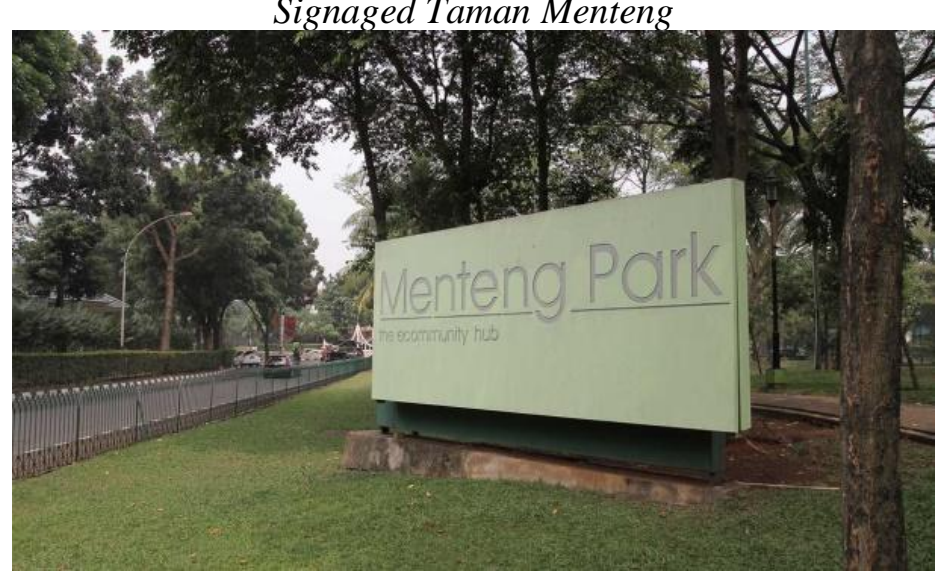

Sumber Gambar: Tim Peneliti. 2019

1. Nama Objek

2. Lokasi

3. Alamat

4. Tanggal dibuka

5. Pengembang

6. Pengelola

7. Total Luas Lahan

8. Batasan Area
: Videotron Taman Menteng Bintaro

: Sektor 7 Bintaro Jaya.

: Jl. Cut Mutia I - Jl. Wahid Hasyim, Pondok Jaya, Kecamatan Pondok Aren, Kota Tangerang Selatan,

: Agustus 2014

: PT Bintaro Jaya

: PT Bintaro Jaya

$: 8.000 \mathrm{~m} 2$

: Jl. Cut Mutia I (Utara), Jl. Menteng Raya (Timur),

Jl. Cut Mutia II (Selatan), Lotte Mart dan CIMB Niaga Office Tower (Barat)

Taman Menteng Bintaro ini lebih nyaman dikunjungi pada waktu pagi atau sore hari. Udara segar dengan banyaknya pepohonan dan hamparan rumput hijau sangat cocok untuk dijadikan area kumpul-kumpul dan bermain. Untuk Anak-anak, terdapat berbagai fasilitas permainan, diantaranya ayunan, jungkat-jungkit, dan perosotan. Selain itu terdapat juga area refleksi kaki berupa jalan dengan batu kerikil dan fasilitas penunjang lain untuk berolahraga dan duduk.

\section{Analisis kondisi lingkungan}

Videotron Taman Menteng Bintaro terletak pada pertigaan jalan Menteng Raya dan Jalan Cut Mutia II, seperti terlihat pada Gambar 2. Dari arah jalan Menteng Raya sampai pertigaan videotron dilalui oleh kendaraan dari 2 arah (garis panah biru dan merah), sedangkan dari arah jalan Cut Mutia II hanya dilalui kendaraan 1 arah (garis panah merah), begitu juga dengan jalan Cut Mutia I menjadi 1 arah (garis panah biru) setelah perpecahan atau pertigaan Taman Menteng Raya dimana lokasi videotron berada. Seperti terlihat pada Gambar 2.

Gambar 2.

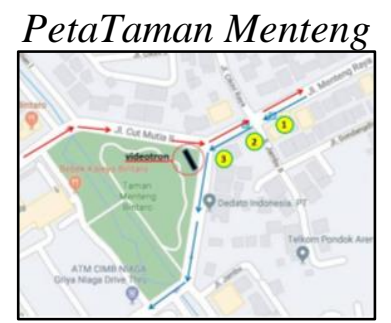

Sumber Gambar: Google maps dan modifikasi tim peneliti, 2019 


\section{Analisis videotron Taman Menteng Bintaro}

Videotron dibuat oleh perusahaan advertising PT. Marka Media pada tahun 2014, area peletakan videotron merupakan lokasi persimpangan dua arah dan pertemuan jalan satu arah dianggap ideal, seperti terlihat pada Gambar 2. pada tahun 2014-2016, jalan belum dibuat pemisah untuk membagi jalan satu arah (jalan Cut Mutia II dan I) dengan pertemuan jalan dua arah (dari dan ke arah jalan Menteng Raya), sehingga sering terjadi kecelakaan. Untuk mengurangi resiko kecelakaan maka dibuat pembatas jalan 2017 dengan menggunakan pembatas cone jalan dan tali, hingga kemudian pada akhir tahun 2017 dibuat pengerasan pembatas jalan menggunakan beton dan taman di tengahnya. Berikut ini adalah spesifikasi videotron pada persimpangan Taman Menteng Bintaro.

Ukuran $\quad: 4 \mathrm{~m} \times 6 \mathrm{~m}(1 \mathrm{Sisi}=24 \mathrm{~m} 2)$

Format : Horisontal

Struktur : Rangka Baja dan Frame Hitam alumunium composit

Keterangan : Very good angle, Heavy and slow moving traffic, ABC class of audienceship, Trading dristrict, Immediate surroundings, Business district, Hotels, Restaurants, Apartment, Residentials Complex, etc.

Gambar 3.

Videotron Taman Menteng Bintaro

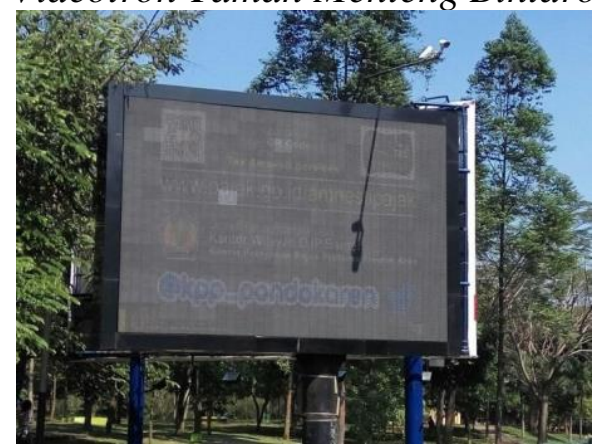

Sumber Gambar: Tim Peneliti. 2019

\section{Observasi videotron dan diskusi}

Observasi dan Pengukuran luminansi dilakukan untuk mengetahui apakah cahaya videotron di Taman Menteng Bintaro memiliki luminansi sesuai dengan kriteria dari SNI pencahayaan buatan ataukah sebaliknya. Berikut ini adalah batasan-batasan pada pengukuran luminansi: (a) Alat pengukuran luminansi yang digunakan adalah Luminance meter dari Lab. Fisika Bangunan Institut Teknologi Bandung merk Lutron dan Luminance meter merk Konica Minolta, (b)Pengukuran dilakukan pada jarak pandang mata manusia dari jalan raya dan menghadap ke sumber cahaya (bidang videotron) untuk keperluan visual dan kecerahan bidang, (c)Jarak pengukuran dibagi menjadi 3, yaitu: 100m, 50m dan 10m (seperti terlihat pada Gambar 2 - lingkaran kuning dengan angka 1, 2 dan 3), dan (d) Perekaman video kondisi cahaya videotron untuk mengetahui pengaruh pencahayaan terhadap konsentrasi pengguna jalan. Pengambilan data kuesioner dilakukan dengan mengambil sampel masing-masing 25 orang pengguna jalan (pejalan kaki dan pengendara kendaraan bermotor).

Pada penelitian ini digunakan beberapa peralatan untuk mengambil data fisis dan visual dari videotron Taman Menteng Bintaro. Berdasarkan data observasi dan pengukuran di lapangan maka dapat disusun sebuah pengelompokan pengaruh pencahayaan terhadap pengguna jalan.

Untuk pengukuran data fisis dan observasi pada jalan digunakan peralatan-peralatan: (a) Kamera DSLR Nikon D3100, (b) Luxmeter, dan (c) Luminance meter merk Konica Minolta. 
Hasil pengambilan foto dan pengukuran luminansi dapat dilihat pada Tabel 1 dan Tabel 2, pengukuran dibagi menjadi 2 kategori waktu yang kontras area dianggap cukup kuat dan aktivitas kendaraan yang padat pada saat jam pulang kantor diantara pukul 17:30 dan pukul 20:00 WIB.

Setelah itu, dilanjutkan dengan proses wawancara dan kuesioner kepada pengguna jalan persimpangan Taman Menteng Bintaro, baik yang dari arah jalan Menteng Raya, maupun dari arah jalan Cut Mutia 2, kuesioner dilakukan dengan mengklasifikasi pengguna jalan yang terdiri dari: pejalan kaki (pedestrian), kendaraan motor roda 2 dan kendaraan motor roda 4.

Hasil kuesioner kemudian dijadikan acuan sebagai kesimpulan evaluasi pencahayaan videotron Taman Menteng Bintaro. Secara keseluruhan penempatan videotron pada persimpangan jalan Taman Menteng Bintaro dianggap biasa saja, bukan hal yang menarik untuk diperhatikan. Tampilan iklan komersial pada videotron Taman Menteng Bintaro dianggap cukup menarik untuk dilihat dan merasa nyaman dengan kondisi pencahayaan yang ada serta pengaruhnya kepada lingkungan sekitar persimpangan Taman Menteng Bintaro. Tetapi dengan tampilan iklan komersial yang secara tiba-tiba berubah warna dari videotron Taman Menteng Bintaro, dirasakan bahwa hampir setengah dari pengguna jalan merasa kaget dan lainnya merasa biasa saja. Efek silau yang dihasilkan dari iklan komersial pada videotron ini (dengan kondisi cahaya yang berubah-ubah secara tiba-tiba) dapat dirasakan oleh hampir semua pengguna jalan.

Tabel 1.

Data fisis luminansi dan foto pada sore hari pukul 17:30.

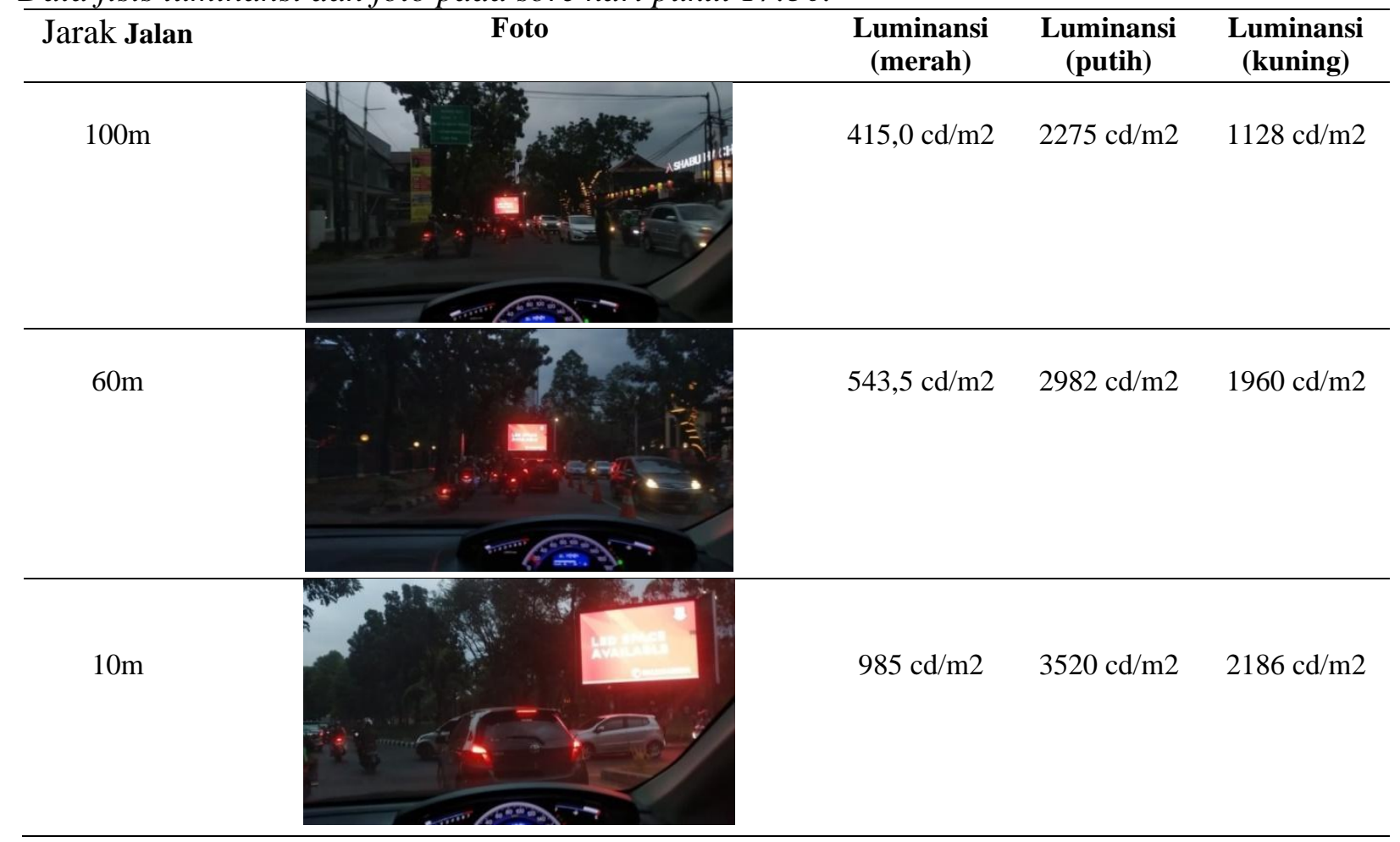


Tabel 2.

Data fisis luminansi dan foto pada malam hari pukul 20:00.

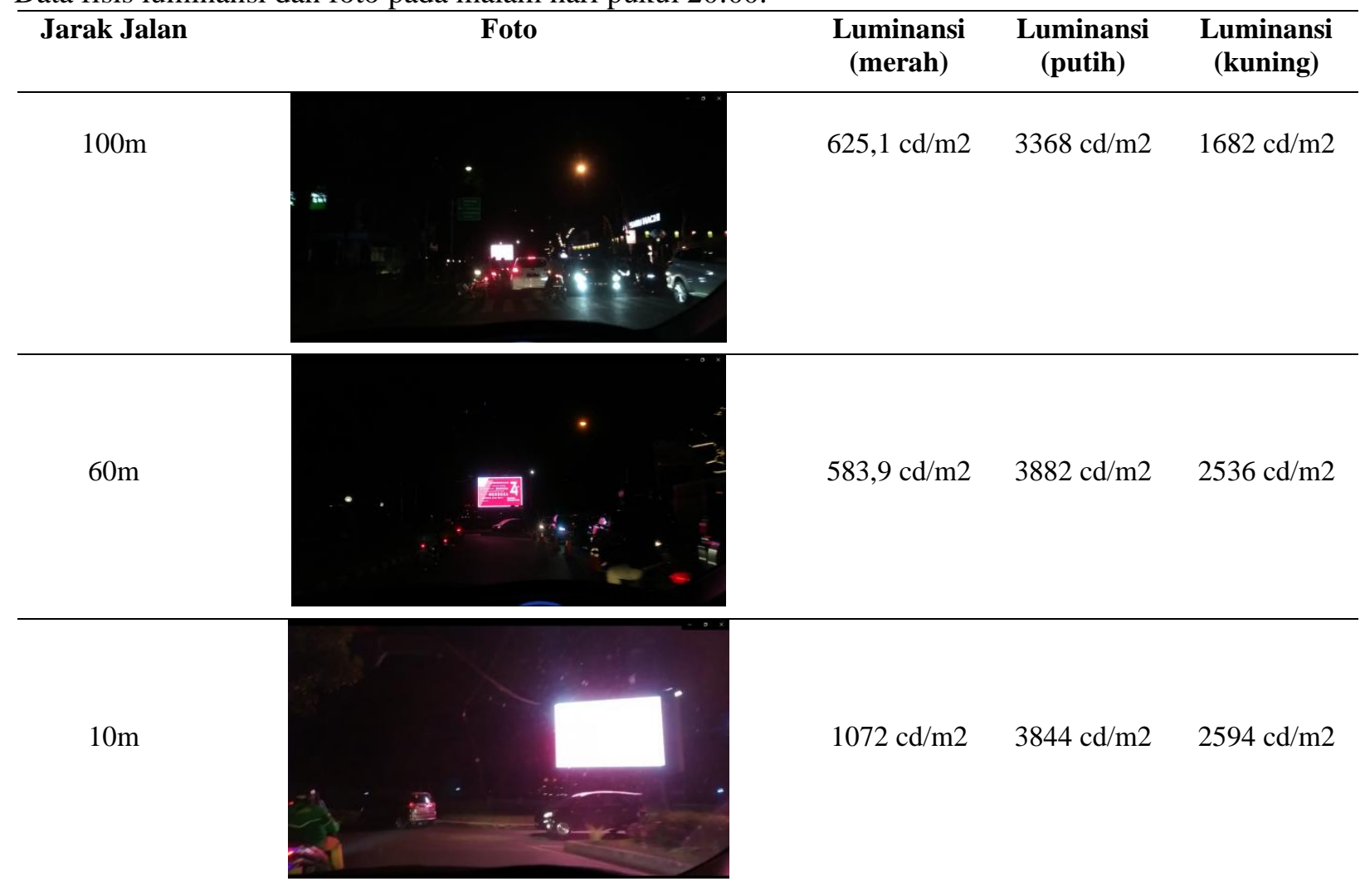

Efek cahaya videotron yang dihasilkan sangat mempengaruhi lingkungan sekitar, diantaranya pada permukaan jalan, permukaan dinding, permukaan kendaraan yang lewat serta tanaman atau pohon. Pengguna jalan pada jarak dari 60 meter hingga mendekati videotron jarak 10 meter jelas akan merasakan efek yang dihasilkan dari cahaya videotron tersebut. Apabila permukaan jalan dalam kondisi reflektif atau hujan, maka efek silau yang dihasilkan akan lebih kuat lagi. Kondisi ini dihasilkan dari perubahan warna cahaya videotron yang terlalu cepat dan drastis melalui tampilan iklan yang bertujuan untuk menarik orang agar melihat langsung isi tampilan iklan yang ada.

Gambar 5.

Perubahan warna cahaya videotron dari arah jalan Menteng Raya jarak 10 meter

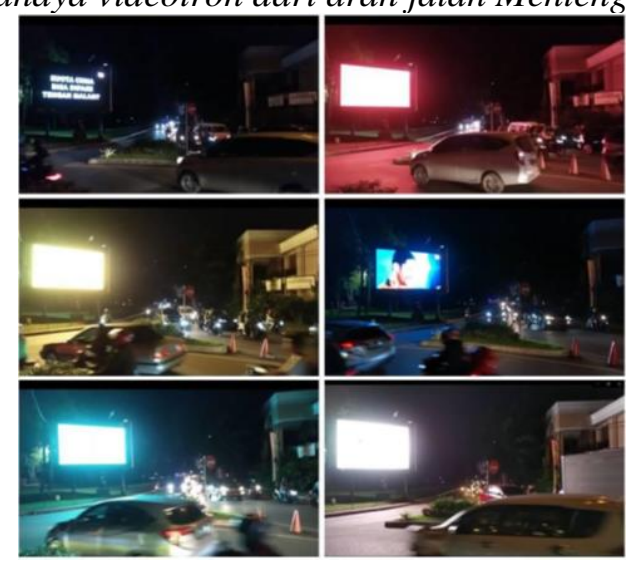

Sumber Gambar: Tim Peneliti. 2019 


\section{KESIMPULAN DAN SARAN}

Informasi iklan komersial yang ditampilkan merupakan hal yang wajar untuk dapat dilihat, dinikmati dan diapresiasi oleh seluruh pengguna jalan. Sebanyak $80 \%$ untuk pejalan kaki dan pengendara mobil mendapatkan informasi iklan komersial, berbanding terbalik dengan pengendara motor sebanyak $60 \%$ tidak mendapatkan informasi apa-apa. Efek pencahayaan yang dihasilkan dari videotron sangat mempengaruhi lingkungan sekitar, terutama pada kondisi pergantian hari dari sore ke malam. Efek cahaya videotron tersebut memantul melalui dinding bangunan, pohon, kendaraan yang lewat serta jalan raya itu sendiri. Hal ini dipengaruhi oleh ketinggian videotron dari permukaan jalan serta jarak dengan bidang pantulan lingkungan sekitar yang terlalu dekat. Perubahan cahaya yang secara tiba-tiba dari tampilan iklan komersial videotron Taman Menteng Bintaro pada dasarnya sangat mengganggu pengguna jalan. Terjadi gangguan pencahayaan berupa efek silau yang dihasilkan, terutama untuk pejalan kaki (80\%), pengendara motor $(60 \%)$ dan paling sedikit dari pengendara mobil (50\%), karena kondisi yang lebih nyaman saat berkendara.

Untuk Pemerintah Daerah, Pengelola lingkungan dan vendor videotron sebaiknya melakukan analisis mengenai dampak akan lingkungan (AMDAL) bukan hanya sebelum menempatkan fasilitas ini, tetapi juga harus mengkaji dampak setelah dalam kondisi terpasang (Post Occupancy Evaluation). Pengelola lingkungan disarankan untuk memperbaiki kondisi batas jalan dimana kemungkinan dapat terjadi resiko kendaraan dengan bentuk pengerasan pembatas jalan, dan juga memberikan peringatan pada jalan raya berupa garis kejut dengan jarak menuju videotron dari 100, 60 dan 10 meter, agar pengguna jalan dapat mengurangi kecepatan kendaraan dan lebih berhati-hati.

Pengelola lingkungan juga dapat membuat kondisi lingkungan yang tidak terlalu kontras dengan fasilitas videotron ini berada pada malam hari, dengan menambahkan lampu jalan atau lampu di sekitar area yang mendekati fasilitas videotron.Tampilan iklan komersial perlu diperhatikan oleh pemilik dan pembuat iklan, agar tidak menghasilkan iklan komersial dengan pencahayaan yang mengganggu, terutama dengan perubahan tampilan cahaya atau grafis yang dibuat secara tiba-tiba, terutama untuk kondisi malam hari.

\section{Ucapan Terima Kasih (Acknowledgement)}

Tim Peneliti mengucapkan terimakasih kepada pihak-pihak terkait yang membantu dalam pelaksanaan penelitian ini, diantaranya Lembaga Penelitian dan Pengabdian kepada Masyarakat, BEM FSRD Untar serta Mitra Pengelola Jaya Bintaro, Bapak Jacob Saragih, M.H., serta para responden pengguna jalan.

\section{REFERENSI}

Association, B. A. (2011). Campaign for Dark Skies (CfDS): Blinded by the Light? Retrieved from http://www.britastro.org/dark-skies/pdfs/HANDBOOKTEXT.pdf.

Badan Standardisasi Nasional. (2020). Pencahayaan buatan. Badan Standardisasi Nasional. http://sispk.bsn.go.id/SNI/DetailSNI/6188.

Badan Standardisasi Nasional. (2020). Sistem Pencahayaan. Badan Standardisasi Nasional. http://sispk.bsn.go.id/SNI/DetailSNI/13243.

Descottes. H., Ramos, C. E. (2012). Architectural lighting: Designing with light and space. Princeton Architectural Press.

Erco. (2014). Efficient LED Light for Public and Outdoor. Lüdenscheid. 
IESNA. (2009). Illuminating Engineering Society of North America, Lighting Handbook, 9th Edition. IES. https://ketpang.ternatekota.go.id/2lu9Z_ies-lighting-handbook-9thedition_gxrC7.pdf.

Karlen, M., Spangler, C., \& Benya, J. R. (2017). Lighting design basics. John Wiley \& Sons.

Liu, M., Fan, Y., Ma, J., \& Zhang, B. (2009, August). Investigation and Experiment of Dynamic Light Disturbance. In 2009 Symposium on Photonics and Optoelectronics (pp. 1-4). IEEE.

Molanaie, E. (2017). The effect of color on urban beautification and peace of citizens. International Journal of Engineering Science Invention, 6(3), 12-16.

Nurfarida, L., Yusup, P. M., \& Komariah, N. (2017). Tingkat Pengetahuan Masyarakat Sekitar Observatorium Bosscha Lembang Mengenai Polusi Cahaya. Jurnal Kajian Informasi \& Perpustakaan, 5(1), 13-22. https://doi.org/10.24198/jkip.v5i1.11327

Phillips, L. (2012): Light and perception, correspondence course lighting application, 5th Edition. Philips Lighting B.V.

Saraiji, R., \& Oommen, M. S. (2012). Light Pollution Index (LPI): An integrated approach to study light pollution with street lighting and façade lighting. Leukos, 9(2), 127-145. https://doi.org/10.1582/LEUKOS.2012.09.02.004

Ulirch, B. (2011). Colour and light, materials for a theory of colour and light. Niggli.

Widyani, A. I. (2016). Persepsi visual terhadap pencahayaan buatan pada secondary skin fasad bangunan komersial mal taman anggrek, Jakarta. Jurnal Visual, 12(1), 14-22.

Zumtobel. (2012). Light for education and science. Zumtobel Lighting GmbH. 